\title{
Is it time to eliminate the use of opioids in cardiac surgery?
}

\author{
Michael C. Grant, MD, MSE, ${ }^{\mathrm{a}, \mathrm{b}}$ Giancarlo Suffredini, MD, ${ }^{\mathrm{a}}$ and Brian C. Cho, MD ${ }^{\mathrm{a}}$
}

Feature Editor Note-Since the early days of cardiac surgery, opiates have been a pillar of intraoperative and postoperative analgesia. The hemodynamic profile of opiates and the nature of cardiac surgery have made this class of analgesics indispensable. Nevertheless, cardiac anesthesia and perioperative cardiothoracic care has evolved dramatically in parallel to the surgical and procedural approaches to heart disease. Despite greater patient acuity and complexity, reducing mechanical ventilation and intensive care unit and hospital length of stay while ensuring patient satisfaction during the recovery process has become imperative. Only recently, however, there has been heightened interest in the quality of early recovery after cardiac surgery, and side effects such as nausea, vomiting, and ileus, all of which are common short-term side effects of opioid-based anesthesia and analgesia, have been part of a new focus of attention. Moreover, with the ongoing opioid crisis, the rate of persistent opioid use after recovery from cardiothoracic surgery, and the irresponsible prescription of opiates after recovery make the case to reevaluate the standard processes that involve opiates, including dose reduction, type of opioid, all the way to envisioning the possibility of opioid-less cardiac anesthesia and perioperative care.

In this issue of the Journal, Dr Michael C. Grant and colleagues explore these possibilities in a provocative and well-written expert opinion paper. The authors start with the background of the opioid-based cardiac anesthetic and the reasons for which opiates have stayed with the practice of cardiac anesthesia for so long. They continue outlining the harmful effects of opioids and make the case for a change, describing the alternatives at our disposal and providing the framework to do it, including a table with the different agents, dosages and side effects.

This expert opinion paper serves as a tool to explore these options and create or participate in studies, so we have more data in the future to reconsider eliminating or significantly reducing opiates in perioperative cardiothoracic care.

\section{Juan N. Pulido, MD}

The anesthetic approach to cardiac surgery has often been described as "opioid-based." More than 5 decades ago,

\footnotetext{
From the Departments of ${ }^{\mathrm{a} A n e s t h e s i o l o g y}$ and Critical Care Medicine, and ${ }^{\mathrm{b}}$ Surgery, The Johns Hopkins Medical Institutions, Baltimore, Md.

Received for publication March 10, 2021; accepted for publication March 10, 2021; available ahead of print April 28, 2021.

Address for reprints: Michael C. Grant, MD, MSE, Johns Hopkins Hospital, 1800 Orleans St, Zayed 6208, Baltimore, MD 21287 (E-mail: mgrant17@jhmi.edu). JTCVS Open 2021;7:247-52

2666-2736

Copyright (C) 2021 The Author(s). Published by Elsevier Inc. on behalf of The American Association for Thoracic Surgery. This is an open access article under the CC BY-NC-ND license (http://creativecommons.org/licenses/by-nc-nd/4.0/).

https://doi.org/10.1016/j.xjon.2021.03.022
}

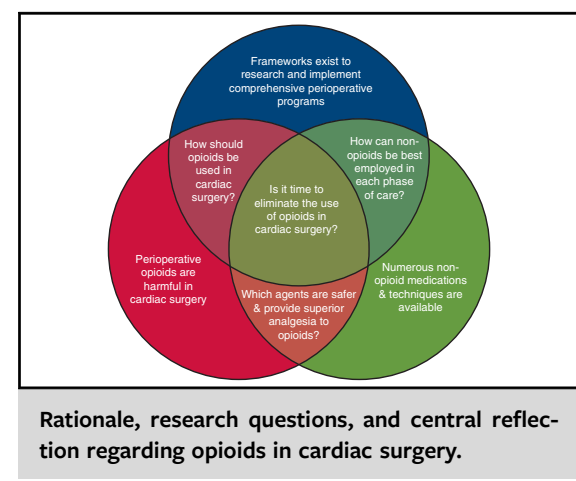

\begin{abstract}
CENTRAL MESSAGE
Opioids are central to cardiac anesthesia and analgesia, but evidence of harm coupled with broader use of multimodal analgesics call for reconsideration of the role of opioids in cardiac surgery.
\end{abstract}

See Commentaries on pages 253,255 , and 257

researchers remarked at the relative hemodynamic stability afforded by the use of large-dose intravenous morphine ( $1 \mathrm{mg} / \mathrm{kg}$ ) for open cardiac procedures. ${ }^{1}$ As one of the cornerstone anesthesia references states, "Opioids lack negative inotropic effects in the doses used clinically and have thus found widespread use as the primary agents for cardiac surgery." 2 With time, morphine has largely been replaced with synthetic alternatives, including fentanyl and sufentanil, due to their heightened potency and even more stable hemodynamic profiles. Recognition of the insufficiency of opioids as a sole agent has contributed to the evolution of the modernday anesthetic, which includes a balanced application of adjuvants to facilitate amnesia (ie, benzodiazepines), anesthetic maintenance (ie, inhaled fluorinated anesthetics, intravenous propofol), and muscle relaxation (ie, paralytics). Despite these notable additions, the relationship between cardiac surgery and opioids remains fully intact, with even "low-dose" regimens describing fentanyl dosing of 10 to $15 \mu \mathrm{g} / \mathrm{kg}$ per patient, a threshold that outpaces the majority of other present-day surgeries.

A CASE FOR CHANGE: OPIOIDS ARE HARMFUL

Recently, there has been great interest in re-evaluating the role of opioids for perioperative care. Much of the 
onus for this movement has stemmed from greater recognition of the harmful side effects associated with their use, including somnolence, nausea and vomiting, and ileus, which are antithetical to the stated objectives of most outpatient, orthopedic, and gastrointestinal surgeries. ${ }^{4}$ In reality, cardiac surgery has long understood the association between excessive opioid use and subsequent delays in postoperative recovery. Fast-track cardiac anesthesia, a hallmark of which entails the reduction in absolute opioid administration, was devised on the promise of hastening time to endotracheal extubation, reducing pulmonary complications, and limiting expenses associated with intensive care. ${ }^{5}$ Interestingly, despite this work, the harmful impacts associated with the use of opioids may well be underreported in the setting of cardiac surgery. Few cardiac programs actively track and report upon opioid-related side effects, even though at least one group revealed a nearly $7 \%$ incidence of gastrointestinal complications. ${ }^{6}$ A recent publication shows that among Medicare beneficiaries undergoing cardiac surgery, although the documented rate of opioid-related adverse drug events (ORADEs) was $0.7 \%$ $(743 / 110,158)$, the potential rate was markedly greater at $32.4 \%(35,658 / 110,158) .^{7}$ The authors go on to show that ORADEs in this setting were associated with longer length of stay, lower reimbursement, and greater health care expense. ${ }^{7}$ It is, therefore, becoming increasingly more difficult to overlook the negative consequences associated with opioid use in cardiac surgery.

Perhaps just as compelling, there is mounting evidence that opioid administration in the initial phases of the surgical encounter increases subsequent opioid requirements later on during hospitalization. Typically associated with chronic opioid exposure, patients can develop tolerance (thereby requiring greater amounts of opioids to achieve similar rates of analgesia) or hyperalgesia (paradoxically developing greater pain sensitivity as a result of escalating doses of opioids). ${ }^{8}$ In contrast to more chronic examples, acute tolerance and opioid-induced hyperalgesia are now commonly recognized, particularly as a consequence of using short-acting opioids such as fentanyl or remifentanil, even in opioid-naïve patients. Ironically, the push to introduce short-acting opioids to cardiac surgery, in the interest of hastening recovery, may be inducing a greater impetus to increase subsequent opioid exposure, both to address-and even perhaps at the expense of-adequate analgesia. Even more vexing, as one review states, tolerance, “....can be unpredictable, with a narrow therapeutic window between desired effects (usually analgesia) and undesirable respiratory or gastrointestinal effects." ${ }^{8}$ As a result, it is highly probable that the rote escalation of opioids will simply expose patients to a greater likelihood of harm rather than more successfully address their pain.

One might imagine that if confined to the immediate perioperative encounter (ie, during hospitalization), certain hospital-based strategies to predict, identify, and mitigate ORADES and lessen the occurrence of acute tolerance and/ or opioid-induced hyperalgesia would suffice. However, more recent data have confirmed that the negative consequences continue on well after discharge. A great deal of attention has been devoted to the fact that perioperative opioid exposure can predispose patients to chronic opioid use. The overwhelming majority of patients are prescribed opioids at the time of discharge, with the risk of misuse, abuse, or diversion all the more amplified with each additional week prescribed. ${ }^{9,10}$ A certain percentage of previously opioid-naïve patients continue to consume opioids 90 to 120 days after surgery, a phenomenon termed new persistent opioid use. Recent studies have revealed that persistent opioid use occurs in $6 \%$ to $15 \%$ of patients who undergo cardiac surgery, among the greatest contributors to chronic opioid use of all subspecialty surgeries. ${ }^{11-13}$ This relationship is directly related to the amount of opioid (ie, morphine sulfate equivalents) prescribed in the immediate postoperative period and on discharge. ${ }^{14}$ Put simply, the cardiac surgical enterprise is experiencing an opioid crisis.

\section{THE CASE FOR CHANGE: THERE ARE ALTERNATIVES}

Although the evidence is mounting to establish the harm associated with opioid use in cardiac surgery, there is cause for optimism. It turns out there are a myriad of reasonable alternatives and techniques both to ensure a balanced, goaldirected anesthetic and achieve optimal perioperative pain management. Anesthetic and analgesic regimens ought to place emphasis on and promote the concurrent use of nonopioid, multimodal medications and techniques, which are repeatedly shown to "have additive, if not synergistic, effects that produce superior analgesia while decreasing opioid use and opioid-related side effects." 15 Viable options include acetaminophen, nonsteroidal anti-inflammatory agents (ie, ibuprofen, intravenous ketorolac), calcium channel modulators (ie, gabapentin, pregabalin), N-methyl-d-aspartate class of glutamate receptor antagonists (ie, ketamine, magnesium), local anesthetics (ie, intravenous lidocaine), and even alpha-2 adrenergic receptor agonists (ie, dexmedetomidine, clonidine). ${ }^{15}$ Regional anesthesia, whether in the form of catheter-based or "single=shot" nerve block techniques, has been essentially overlooked in the setting of cardiac surgery, despite both the success of its application to other surgical subspecialties and the relative breadth and simplicity of the potential approaches. ${ }^{16}$ These various agents and techniques have been underused in the setting of cardiac surgery, lend themselves to application in all phases of care (ie, pre-, intra-, and postoperative), and represent a true opportunity to shift away from opioids as first (or even second)-line agents for pain management.

Whereas each nonopioid has independently been shown to reduce perioperative opioid administration without 
expensing optimal analgesia, it is admittedly oversimplified to suggest those results will immediately translate to cardiac surgery. Patients who undergo cardiac surgery not only tend to be older and frailer, but they experience a greater incidence of postoperative delirium, organ injury (ie, acute kidney injury), arrhythmia, and hemodynamic instability compared with other subspeciality surgeries. ${ }^{17}$ These unique patient and procedure characteristics have direct implications on the viability of individual agents for cardiac surgery. As a result, it is important to acknowledge certain limitations to each medication or technique, as outlined in Table $1 .^{16,18-21}$ Furthermore, providing a battery of medications requires appropriate monitoring and expertise to surveil, identify, and prevent the ills associated with various side effects, drug-drug interactions, and polypharmacy. Whereas a host of research has been published on efficacy and safety profiles of opioid-sparing strategies in general surgery, comparatively minimal investigation has been devoted to the topic as it pertains to the cardiac surgical population.

\section{THE CASE FOR CHANGE: FRAMEWORKS EXIST FOR RESEARCH AND IMPLEMENTATION}

It is in the area of research and implementation that the development of a comprehensive perioperative care delivery program, such as Enhanced Recovery After Surgery (ERAS), can provide value when applied to the cardiac landscape. ERAS programs, which involve the phasespecific, bundled application of numerous evidence-based interventions throughout the surgical encounter, are designed to mitigate the stress associated with surgical insult, hasten recovery, and reduce preventable harms associated with more conventional care. ${ }^{22} \mathrm{~A}$ foundational aspect of ERAS programs is the recruitment of a multidisciplinary team, including stakeholders from surgery, anesthesiology, nursing, clinical pharmacy, and acute pain management, among others, to protocolize (where appropriate) desired technical patient care components. Drawing upon this diverse expertise ensures patients not only receive core interventions such as nonopioid medications but are similarly highlighted in the event they present with contraindications to those interventions. Systems engineers, who are tasked with the design and implementation of similar complex programs, would support this brand of consensus building and protocolization as a means to reduce unwanted variation (ie, inconsistent or disparate care), but ensure wanted variation (ie, avoid inappropriate application of protocol elements to high-risk individuals). ${ }^{23}$

Momentum around and evidence for nonopioid analgesia is supported by the consensus guideline put forward

TABLE 1. Nonopioid medications and techniques

\begin{tabular}{|c|c|c|}
\hline Agent class (mechanism) & $\begin{array}{l}\text { Recommended dosing (phase-of-care of } \\
\text { administration) }\end{array}$ & $\begin{array}{c}\text { Limitation(s) }{ }^{21} \text { particularly as associated } \\
\text { with cardiac surgery }\end{array}$ \\
\hline acetaminophen (unknown; COX inhibitor?) & $\begin{array}{l}\text { 650-1000 mg PO every 6- } 8 \mathrm{~h} \text { scheduled; max } \\
3 \mathrm{~g} / 24 \mathrm{~h} \text { (pre-, intra-, or postoperative) }\end{array}$ & Liver toxicity \\
\hline NSAIDS (nonspecific COX inhibitor) & $\begin{array}{l}\text { Ketorolac [IV]: } 15-30 \mathrm{mg} \text { every } 6-8 \mathrm{~h} \\
\text { scheduled (postoperative) } \\
\text { Ibuprofen [PO]: } 400-800 \mathrm{mg} \text { every } 6-8 \mathrm{~h} \\
\text { scheduled (postoperative) }\end{array}$ & $\begin{array}{l}\text { Platelet dysfunction; gastrointestinal } \\
\text { irritation; renal dysfunction; "black-box } \\
\text { warning" in the setting of } \mathrm{CABG}^{18}\end{array}$ \\
\hline dexmedetomidine (alpha-2 agonist) & $\begin{array}{l}0.5-1.5 \mu \mathrm{g} / \mathrm{kg} / \mathrm{h} \text { infusion (intra-, } \\
\text { postoperative) }\end{array}$ & Hypotension, bradycardia \\
\hline $\begin{array}{l}\text { Gabapentinoids (voltage gated calcium } \\
\text { channel modulator) }\end{array}$ & $\begin{array}{l}\text { Gabapentin: } 300-600 \mathrm{mg} \text { (pre); } 100-300 \mathrm{mg} \\
\text { every } 8 \mathrm{~h} \text { scheduled (postoperative) } \\
\text { Pregabalin: } 50-150 \mathrm{mg} \text { (preoperative); } 50- \\
\quad 150 \mathrm{mg} \text { every } 8 \mathrm{~h} \text { scheduled } \\
\text { (postoperative) }\end{array}$ & $\begin{array}{l}\text { Gabapentin: dizziness, sedation, respiratory } \\
\text { depression, renally excreted, questionable } \\
\text { efficacy }{ }^{19} \\
\text { Pregabalin: altered vision, renally excreted }\end{array}$ \\
\hline $\begin{array}{l}\text { lidocaine [IV] (voltage-gated sodium channel } \\
\text { inhibitor) }\end{array}$ & $\begin{array}{l}1 \mathrm{mg} / \mathrm{kg} \text { bolus (intra); } 0.5-2.0 \mathrm{mg} / \mathrm{kg} / \mathrm{h} \\
\text { infusion (intra-, postoperative) }\end{array}$ & $\begin{array}{l}\text { Optimal dosage regimen uncertain, local } \\
\text { anesthetic toxicity monitoring, risk for } \\
\text { seizure }\end{array}$ \\
\hline ketamine (N-methyl-D-aspartate antagonist) & $\begin{array}{l}0.1-1.0 \mathrm{mg} / \mathrm{kg} \text { bolus (intra-); } 0.1-0.2 \mathrm{mg} / \mathrm{kg} / \mathrm{h} \\
\text { infusion (intra-, postoperative) }\end{array}$ & $\begin{array}{l}\text { Tachycardia (bolus), questionable efficacy, } \\
\text { optimal dosage regimen uncertain }^{20}\end{array}$ \\
\hline regional analgesia & $\begin{array}{l}\text { "Sngle shot": serratus anterior } \\
\text { [thoracotomy], transverse thoracic plane, } \\
\text { parasternal, pectoralis nerve block } \\
\text { [sternotomy] (intraoperative) catheter- } \\
\text { based: erector spinae (pre-, intra-, } \\
\text { postoperative) }\end{array}$ & $\begin{array}{l}\text { Failure of technique, local anesthetic toxicity, } \\
\text { unclear efficacy, wide variation in block } \\
\text { type as well as local type and infusate } \\
\text { adjuncts, }{ }^{16} \text { special provider training } \\
\text { necessary }\end{array}$ \\
\hline
\end{tabular}

COX, Cyclooxygenase; $P O$, per os; $N S A I D s$, nonsteroidal anti-inflammatory agents; $I V$, intravenous; $C A B G$, coronary artery bypass grafting. 
by the ERAS Cardiac Society, who recommend the use of a "perioperative, multimodal, opioid-sparing, pain management plan." 24 Although they stop short of outlining how such a plan might be achieved, there are at least 2 observational cohorts who have published compelling examples of their multimodal pain strategies in cardiac surgery. The first provided a combination of dose-adjusted gabapentin and acetaminophen before and in a scheduled fashion following surgery. Based on a before-after analysis, they reported a significant reduction in postoperative opioids, as well as a nearly $50 \%$ reduction in rates of gastrointestinal complications. ${ }^{6}$ Another group evaluated the results of the initial preanesthesia and intraoperative phases of an enhanced recovery program for cardiac surgery, which included the preoperative administration of dose-adjusted gabapentin and acetaminophen, as well as intraoperative subhypnotic ketamine, dexmedetomidine, and regional analgesia. ${ }^{25,26}$ Increased compliance with the outline revealed an inverse relationship with absolute intraoperative opioid exposure, with numerous patients achieving an "ultra-low" level of opioid $(\leq 25$ morphine sulfate equivalents) and a handful of patients managed entirely opioid-free. ${ }^{26}$ This lattermost finding suggests that not only are there comprehensive strategies to consistently limit opioids, but that optimal anesthesia and analgesia for cardiac surgery is feasible without opioids altogether.

\section{TECHNICAL AND ADAPTIVE COMPONENTS ARE EQUALLY VITAL}

A full appraisal of existing ERAS programs for cardiac surgery is incomplete without acknowledging that success is underpinned equally by the careful selection of their bundled technical interventions as well as their more adaptive components. Williams and colleagues ${ }^{6}$ incorporated the Knowledge-to-Action framework for implementation, which assesses and adapts interventions based upon local barriers and enablers, including unit culture and key stakeholder perspectives. Grant and colleagues ${ }^{25}$ was grounded in the Comprehensive Unit-based Safety Program, a model for intervention that relies heavily on nursing, advanced provider, and bedside physician grassroots implementation, which empowers front-line providers to reinforce a culture of safety and patient-centered care. As Salenger and colleagues $^{22}$ describe in a recent guide for ERAS implementation, "Several core principles transcend all ERAS cardiac programs. Implementation of cardiac ERAS is more than simply the installation of a protocol. ERAS involves a methodical shift in culture..." Marrying the technical and adaptive components is essential to establishing a culture that recognizes the harms of opioid administration and strives to seek thoughtful alternatives.

Unfortunately, ERAS programs are not a panacea. The literature is replete with examples of ERAS for noncardiac surgery, including those who have provided descriptions of

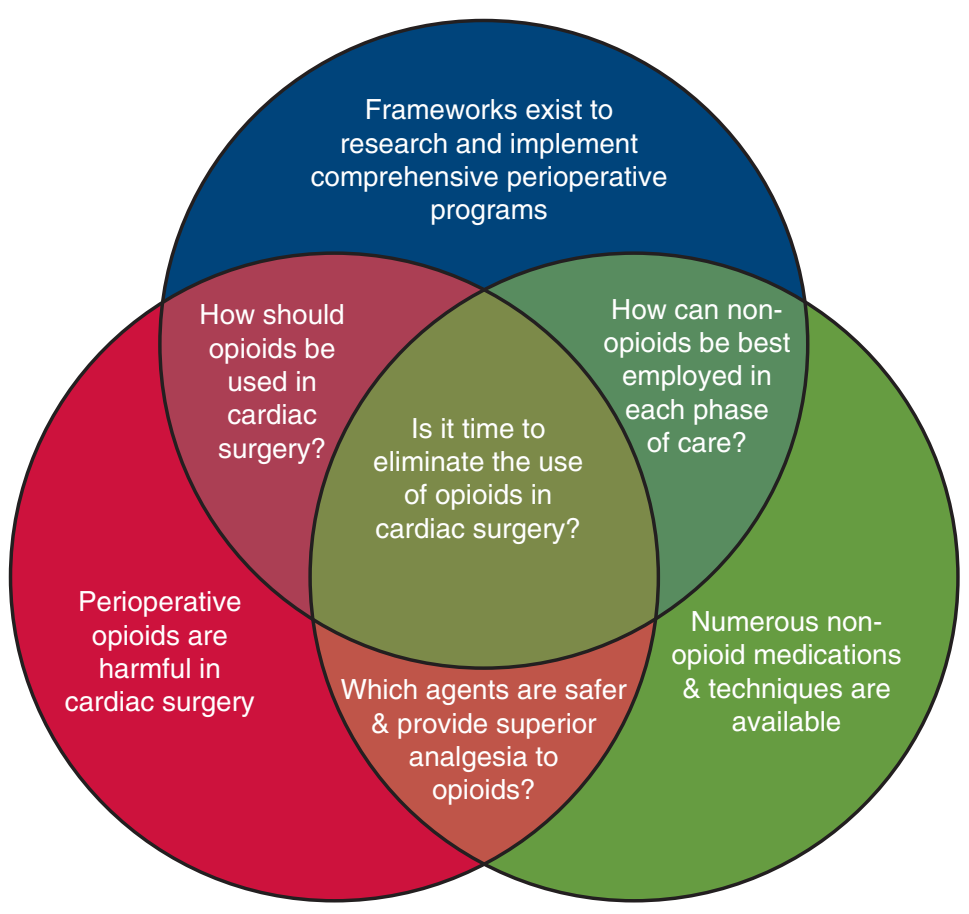

FIGURE 1. Reconsideration of the role of opioids in cardiac surgery stems from evidence of their early- and long-term harm as well as our ability to leverage perioperative systems designed to research and implement multimodal analgesic medications and techniques. 
entire surgical encounters (ie, preoperative phase to time of discharge) which were opioid-free. Incredibly, despite those efforts, patients were still prescribed the same number of opioids on discharge. ${ }^{27}$ This serves to highlight the potential disconnect between care provided in one phase compared with another, as well as the lack of support for discharge transitioning and prescription management. Although strategies have been articulated, including real-time assessment, conversion and calculation of opioid requirements, de-escalation of opioid dosing, prescription monitoring and pill counting, among others, ${ }^{28}$ there simply are not robust networks that have been created to ensure adequate post discharge analgesia, yet reasonably monitor and intervene on risky behavior where necessary. There is, admittedly, a great deal more work to be done to devise creative solutions to track opioid administration, both during hospitalization and thereafter.

\section{CONCLUSIONS}

Looking forward, clinician researchers are tasked with several important objectives (Figure 1). Despite the harms associated with opioids and the opportunity afforded by the various alternatives, examples of opioid-free anesthesia and analgesia in the cardiac surgical setting are thus far limited to case reports and small subsets of observational cohorts. $^{26,29-31}$ Certainly, to garner more widespread support, opioid-free (or even opioid-sparing) strategies need not only establish feasibility, but identify and promote algorithms that have both similar analgesic efficacy as well as greater safety profiles than the present approach. It is also important to admit that opioids are not inherently evil. When used as they were originally intended (ie, to address pain that is otherwise unmanageable with alternative means, applied in the lowest effective dose for the shortest period possible), opioids may still represent an important arrow in the quiver of perioperative pain control.

Cardiac surgery enjoys a rich history of innovation, including the incorporation of cardiopulmonary bypass, minimally invasive techniques, transcatheter technology, indwelling mechanical support devices, and more. The discipline has long been a thought leader in perioperative pathway development and implementation. Based on the evidence of harm associated with opioid use, the collection of viable nonopioid alternatives and the multidisciplinary frameworks at our disposal, it is time to devise research strategies and establish innovative clinical programs that both advance our understanding of opioid minimization and reconsider altogether the role of opioids in cardiac surgery.

\section{Conflict of Interest Statement}

Michael C. Grant reports he holds a nonremunerated position of influence, Executive Board Member - Enhanced Recovery After Surgery Cardiac Society. All other authors reported no conflicts of interest.
The Journal policy requires editors and reviewers to disclose conflicts of interest and to decline handling or reviewing manuscripts for which they may have a conflict of interest. The editors and reviewers of this article have no conflicts of interest.

\section{References}

1. Lowenstein E, Hallowell P, Levine FH, Daggett WM, Austen WG, Laver MB. Cardiovascular response to large doses of intravenous morphine in man. $N$ Engl J Med. 1969:281:1389-93.

2. Skubas NJ, Lichtman AD, Wang CJ. Anesthesia for cardiac surgery. In: Paul G, Barash PG, Cullen BF, Stoelting RK, Stock MC, Stoelting RK, Ortega R, et al., eds. Clinical Anesthesia. 8th ed. Philadelphia: Walters Kluwer; 2017:1077-11.

3. Silbert BS, Scott DA, Evered LA, Lewis MS, Kalpokas M, Maruff P, et al. A comparison of the effect of high- and low-dose fentanyl on the incidence of postoperative cognitive dysfunction after coronary artery bypass surgery in the elderly. Anesthesiology. 2006;104:1137-45.

4. Dasinger EA, Branch-Elliman W, Pizer SD, Abdulkerim H, Rosen AK, Charns MP, et al. Association between postoperative opioid use and outpatient surgical adverse events. Am J Surg. 2019;217:605-12.

5. Myles PS, Daly DJ, Djaiani G, Lee A, Cheng DC. A systematic review of the safety and effectiveness of fast-track cardiac anesthesia. Anesthesiology. 2003; 99:982-7.

6. Williams JB, McConnell G, Allender JE, Woltz P, Kane K, Smith PK, et al. Oneyear results from the first US-based enhanced recovery after cardiac surgery (ERAS Cardiac) program. J Thorac Cardiovasc Surg. 2019;157:1881-8.

7. Allen KB, Brovman EY, Chhatriwalla AK, Greco KJ, Rao N, Kumar A, et al. Opioid-related adverse events: incidence and impact in patients undergoing cardiac surgery. Semin Cardiothorac Vasc Anesth. 2020;24:219-26.

8. Colvin LA, Bull F, Hales TG. Perioperative opioid analgesia-when is enough too much? A review of opioid-induced tolerance and hyperalgesia. Lancet. 2019; 393:1558-68.

9. Wunsch H, Wijeysundera DN, Passarella MA, Neuman MD. Opioids prescribed after low-risk surgical procedures in the United States, 2004-2012. JAMA. 2016; 315:1654-5.

10. Brat GA, Agniel D, Beam A, Yorkgitis B, Bicket M, Homer M, et al. Postsurgical prescriptions for opioid naive patients and association with overdose and misuse: retrospective cohort study. BMJ. 2018;360:j5790.

11. Brescia AA, Waljee JF, Hu HM, Englesbe MJ, Brummett CM, Lagisetty PA, et al. Impact of prescribing on new persistent opioid use after cardiothoracic surgery Ann Thorac Surg. 2019;108:1107-13.

12. Clement KC, Canner KJ, Lawton JS, Whitman GJR, Grant MC, Sussman MS Predictors of new persistent opioid use after coronary artery bypass grafting. $J$ Thorac Cardiovasc Surg. 2020;160:954-63.e4.

13. Clement KC, Canner JK, Whitman GJR, Lawton JS, Grant MC, Sussman MS New persistent opioid use after aortic and mitral valve surgery in commercially insured patients. Ann Thorac Surg. 2020;110:829-35.

14. Brown CR, Chen Z, Khurshan F, Groeneveld PW, Desai ND. Development of persistent opioid use after cardiac surgery. JAMA Cardiol. 2020;5:889-96.

15. Wick EC, Grant MC, Wu CL. Postoperative multimodal analgesia pain management with nonopioid analgesics and techniques: a review. JAMA Surg. 2017;152 691-7.

16. Mittnacht AJC, Shariat A, Weiner MM, Malhotra A, Miller MA, Mahajan A, et al. Regional techniques for cardiac and cardiac-related procedure. J Cardiothorac Vasc Anesth. 2019;33:532-46.

17. D'Agostino RS, Jacobs JP, Badhwar V, Fernandez FG, Paone G, Wormuth DW et al. The Society of Thoracic Surgeons Adult Cardiac Surgery Database: 2018 Update on Outcomes and Quality. Ann Thorac Surg. 2018;105:15-23.

18. US Food and Drug Administration. Medication guide for nonsteroidal antiinflammatory drugs (NSAIDs); 2020. Available at: https://www.fda.gov/media/ 72932/download\#: : text=Do $\% 20$ not $\% 20$ take $\%$ 20NSAIDs $\% 20$ right, after $\%$ 20a\%20recent $\%$ 20heart \%20attack. Accessed February 10, 2021.

19. Verret M, Lauzier F, Zarychanski R, Perron C, Savard X, Pinard AM, et al. Perioperative use of gabapentinoids for the management of postoperative acute pain: a systematic review and meta-analysis. Anesthesiology. 2020;133:265-79.

20. Avidan MS, Maybrier HR, Abdallah AB, Jacobsohn E, Vlisides PE, Pryor KO et al. Intraoperative ketamine for prevention of postoperative delirium or pain after major surgery in older adults: an international, multicentre, double-blind, randomised clinical trial. Lancet. 2017;390:267-75. 
21. Wu CL, King AB, Geiger TM, Grant MC, Grocott MPW, Gupta R, et al. American Society for Enhanced Recovery and perioperative quality initiative joint consensus statement on perioperative opioid minimization in opioid-naïve patients. Anesth Analg. 2019;129:567-77.

22. Salenger R, Morton-Bailey V, Grant M, Gregory A, Williams JB, Engelman DT. Cardiac Enhanced Recovery After Surgery: a guide to team building and successful implementation. Semin Thorac Cardiovasc Surg. 2020;32:187-96.

23. Kossiakoff A, Sweet WN, Seymour SJ, Biemer SM. Systems Engineering Principles and Practice. 2nd ed. Hoboken: Wiley-Interscience; 2011.

24. Engelman DT, Ben Ali W, Williams JB, Perrault LP, Reddy VS, Arora RC, et al. Guidelines for perioperative care in cardiac surgery: Enhanced Recovery After Surgery Society Recommendations. JAMA Surg. 2019;154:755-66.

25. Grant MC, Isada T, Ruzankin P, Whitman G, Lawton JS, Dodd -OJ, et al. Results from an Enhanced Recovery Program for cardiac surgery. J Thorac Cardiovasc Surg. 2019;159:1392-402.

26. Grant MC, Isada T, Ruzankin P, Gottschalk A, Whitman G, Lawton JS, et al. Opioid-sparing cardiac anesthesia: secondary analysis of an Enhanced Recovery Program for cardiac surgery. Anesth Analg. 2020;131:1852-61.

27. Brandal D, Keller MS, Lee C, Grogan T, Fujimoto Y, Gricourt Y, et al. Impact of Enhanced Recovery After Surgery and opioid-free anesthesia on opioid prescrip- tions at discharge from the hospital: a historical-prospective study. Anesth Analg. 2017; 125:1784-92.

28. Kent ML, Hurley RW, Oderda GM, Gordon DB, Sun E, Mythen M, et al. American Society for Enhanced Recovery and Perioperative quality initiative4 joint consensus statement on persistent postoperative opioid use: definition, incidence, risk factors, and health care system initiatives. Anesth Analg. 2019; 129:543-52.

29. Guinot PG, Spitz A, Berthoud V, Ellouze O, Missaoui A, Constandache T, et al. Effect of opioid-free anaesthesia on post-operative period in cardiac surgery: a retrospective matched case-control study. BMC Anesthesiol. 2019;19:136.

30. Landry E, Burns S, Pelletier MP, Muehlschlegel JD. A successful opioid-free anesthetic in a patient undergoing cardiac surgery. J Cardiothorac Vasc Anesth. 2019;33:2517-20.

31. Chanowski EJP, Horn JL, Boyd JH, Tsui BCH, Brodt JL. Opioid-free ultra-fasttrack on-pump coronary artery bypass grafting using erector spinae plane catheters. J Cardiothorac Vasc Anesth. 2019;33:1988-90.

Key Words: opioids, nonopioid analgesia, multimodal analgesia, Enhanced Recovery After Surgery 